\title{
EDUCAÇÃO EMPREENDEDORA: PRÁTICAS EDUCATIVAS PARA DINAMIZAR A ASCENSÃO PESSOAL E PROFISSIONAL DOS ALUNOS
}

\author{
EDUCACIÓN EMPRENDEDORA: PRÁCTICAS EDUCATIVAS PARA \\ DINAMIZAR LA ASCENSIÓN PERSONAL Y PROFESIONAL DE LOS \\ ALUMNOS
}

\begin{abstract}
ENTREPRENEURIAL EDUCATION: EDUCATIONAL PRACTICES FOR DYNAMIZING THE PERSONAL AND PROFESSIONAL ASCENSION OF STUDENTS
\end{abstract}

\author{
Fábio Tadeu REINA ${ }^{1}$ \\ Roberto Augusto dos SANTOS ${ }^{2}$
}

RESUMO: No passado, a criação de empresas era assunto para adultos, mas hoje os jovens também pensam em negócios próprios como opção de carreira. Diante disso, as escolas, principalmente de ensinos fundamental e médio, precisam refletir sobre práticas educativas que dinamizam o empreendedorismo para apoiar a ascensão pessoal e profissional dos educandos. Nesse contexto, esse artigo apresenta, por meio de pesquisas bibliográfica, documental e analítico-descritiva, uma proposta com objetivos, conteúdos e estratégias de ensino, para dinamizar a educação empreendedora nos ambientes escolares. Espera-se, com isso, o fornecimento de subsídios para alicerçar o planejamento didático das escolas com interesse nessa temática, principalmente das que querem novos desafios para prover as pessoas de novos saberes.

PALAVRAS-CHAVE: Empreendedorismo. Educação empreendedora. Jovens. Práticas educativas.

RESUMEN: En el pasado, la creación de empresas era asunto para adultos, pero hoy los jóvenes también piensan en negocios propios como opción de carrera. Por lo tanto, las escuelas, principalmente de enseñanza fundamental y media, necesitan reflexionar sobre prácticas educativas que dinamizan el espíritu emprendedor para apoyar el ascenso personal y profesional de los educandos. En este contexto, este artículo presenta, por medio de investigaciones bibliográfica, documental y analíticodescriptiva, una propuesta con objetivos, contenidos y estrategias de enseñanza, para dinamizar la educación emprendedora en los ambientes escolares. Se espera, con ello, el suministro de subsidios para fundamentar la planificación didáctica de las escuelas

\footnotetext{
${ }^{1}$ Centro Universitário de Araraquara (UNIARA), Araraquara - SP - Brasil. Professor titular do Centro Universitário de Araraquara, professor efetivo da rede básica do ensino do Estado de São Paulo e professor de educação física efetivo da Secretaria Municipal de Esportes e lazer de Araraquara , atuando principalmente nos seguintes temas: enfrentamento à violência simbólica, educação física escolar, inclusão social, desigualdade cultural, teoria na educação física, gestão e políticas educacionais. Doutor em Educação pelo PPG em Educação Escolar, FCLAr/Unesp. E-mail: ftreina@ @otmail.com

${ }^{2}$ Centro Universitário de Araraquara (UNIARA), Araraquara - SP - Brasil. E-mail: gutoblv@gmail.com
} 
con interés en esta temática, principalmente de las que quieren nuevos desafíos para proveer a las personas de nuevos saberes.

PALABRAS-CLAVE: Emprendedorismo. Educación emprendedora. Jóvenes.

Prácticas educativas.

ABSTRACT: In the past, business creation was a matter for adults, but today young people also think of their own business as a career choice. Faced with this, schools, especially primary and secondary schools, need to reflect on educational practices that dynamize entrepreneurship to support the personal and professional advancement of learners. In this context, this article presents, through bibliographical, documentary and analytical-descriptive research, a proposal with objectives, contents and teaching strategies, to dynamize the entrepreneurial education in school environments. It is hoped, therefore, to provide subsidies to support the didactic planning of schools with an interest in this subject, especially those that want new challenges to provide people with new knowledge.

KEYWORDS: Entrepreneurship. Entrepreneurial education. Young. Educational practices.

\section{Introdução}

$\mathrm{Na}$ contemporaneidade, a educação de jovens requer múltiplos desafios, um deles relaciona-se a prepará-los melhor para o mercado de trabalho, incluindo a criação de novos negócios como opção de carreira profissional. Se antes, as orientações concentravam-se na perspectiva deles atuarem somente como empregados em grandes organizações, hoje o empreendedorismo é realidade entre eles, até porque os países precisam de novas empresas, principalmente de pequeno porte, para gerar emprego e renda, consequentemente desenvolverem-se social e economicamente. Dornelas (2008) comenta que no passado não era comum um jovem recém-formado aventurar-se na criação de um negócio próprio, pois os empregos oferecidos pelas grandes empresas eram muito convidativos. Em contrapartida, o cenário atual é bem diferente, visto que a revista Exame $^{3}$ (2014) mostra que os jovens brasileiros querem negócios próprios, pois $57 \%$ se imaginam como possíveis empregadores, $27 \%$ estão indecisos e $16 \%$ se veem como possíveis empregados. Nesse ambiente, é preciso refletir, incessantemente, sobre práticas educativas que dinamizam as competências necessárias à atuação dos jovens como empreendedores.

\footnotetext{
${ }^{3}$ Revista Exame: Pesquisa realizada pelo Instituto Brasileiro de Opinião Pública e Estatística (IBOPE) e
} pela Universidade de São Paulo (USP), a pedido da Fundação Telefônica Vivo. 
No Brasil, o empreendedorismo é estimulado nas universidades desde a década de 1990, mas é preciso avançar essa questão em outras instâncias educacionais. Isso não quer dizer que não há iniciativas nesse sentido, mas ainda são modestas diante das expectativas acerca dessa temática. Atualmente, discutem-se no senado o projeto de lei ${ }^{4}$ do senador José Agripino que propõe a inclusão do empreendedorismo, como tema transversal, nos conteúdos curriculares da educação básica. Se isso acontecer, novos ingredientes educacionais farão parte dos componentes curriculares das escolas, que precisam se antecipar a essa nova realidade.

Nesse contexto, esse artigo evidencia a educação empreendedora e propõe práticas educativas que impulsionam as competências empreendedoras dos jovens. Desse modo, busca, essencialmente, respostas às seguintes questões: quais objetivos conteúdos e estratégias de ensino podem ser utilizados no âmbito da educação empreendedora? Sabe-se que novos desafios impõem restruturações nas formas organizativas das instituições, e a escola não se isenta disso, ao contrário, é ela quem dinamiza novos saberes, necessários a adaptação das pessoas diante das mudanças. Libâneo (2013) ressalta a importância de a educação atender as necessidades coletivas, já que a educação é um fenômeno social, por isso deve prover os indivíduos de saberes para atuarem frente às necessidades econômicas, políticas e sociais.

Enfim, o empreendedorismo enraíza-se, paulatinamente, nos espaços escolares, mas é preciso ampliar a discussão desse tema para programar atividades educacionais consistentes em vez de ações paliativas, que somente estimulam, mas não desenvolvem, de fato, as competências empreendedoras requeridas.

\section{Materiais e métodos}

Para responder as indagações desse artigo foram utilizados três tipos de pesquisa: a bibliográfica, a documental e a analítico-descritiva. A pesquisa bibliográfica fundamentou conceitos concernentes à educação empreendedora. Já, as demais possibilitaram à confecção da proposta de práticas educativas essenciais à promoção do empreendedorismo no ambiente escolar.

${ }^{4}$ AGÊNCIA SENADO. Empreendedorismo pode passar a ser ensinado nas escolas. Disponível em: http://www12.senado.leg.br/noticias/materias/2015/12/29/empreendedorismo-pode-passar-a-serensinado-nas-escolas. Acesso em: 18 jan. 2016. 
Diversos recursos informacionais foram utilizados para enaltecer os objetivos, os conteúdos e as estratégias de ensino acerca da temática evidenciada, mas os principais foram: o livro "Educação empreendedora: conceitos, modelos e práticas", de Lopes et. al. (2010); o artigo “Characteristics of Successful Entrepreneurs" de McClelland (1987); e dois materiais do Instituto Centro de Capacitação e Apoio ao Empreendedor (CAPE) - a apostila do repasse do jogo Business expenses savings training game (Best Game) e o manual do facilitador.

A pesquisa de McClelland (1987) e o jogo empresarial Best Game foram escolhidos porque ainda são referências, desde que criados, para dinamizar a cultura empreendedora no Brasil e no mundo. Os comportamentos empreendedores enaltecidos por McClelland (1987), por exemplo, serviram de base à $\mathrm{ONU}^{5}$ - em parceria com a $\mathrm{MSI}^{6}$ - para estruturar o seminário EMPRETEC.

No Brasil, esse seminário, voltado ao desenvolvimento das características empreendedoras, é realizado pelo SEBRAE ${ }^{7}$, em parceria com $\operatorname{PNUD}^{8}{ }^{8}$ a $\mathrm{UNCTAD}^{9}$ e a ABC. ${ }^{10}$ Desde 1993, já passaram mais de oito mil turmas de formação organizadas em todos os Estados do país, fazendo do Brasil um líder mundial de capacitação (ONUBR, 2013).

Já, o Best Game foi criado na África do Sul pela TTO ${ }^{11}$ em 1991 para fomentar pequenos negócios com estratégias de ensino baseadas em aprendizagens por meio da ação. Em 1995, a OIT ${ }^{12}$ incorporou esse jogo em seus projetos de criação de novos negócios; em 1996 foi apresentado no encontro mundial $\mathrm{CEFE}^{13}$ - organizado pela GTZ $^{14}$ da Alemanha; em 1997, o Centro CAPE adquiriu os direitos de distribuição no Brasil. Hoje, essa metodologia está em mais de 60 países e o Centro CAPE é referência no repasse dela no Brasil (CAPE s/data).

Os recursos mencionados, até então, foram utilizados para evidenciar a educação empreendedora. Já, as práticas educativas, propostas nessa pesquisa, foram organizadas

${ }^{5}$ ONU - Organização das Nações Unidas.

${ }^{6}$ MSI - Management Systems International

${ }^{7}$ SEBRAE - Serviço de apoio as Micro e Pequenas Empresas.

${ }^{8}$ PNUD - Programa das Nações Unidas para o desenvolvimento.

${ }^{9}$ UNCTAD - Conferência das Nações Unidas para o Comércio e Desenvolvimento

${ }^{10}$ ABC - Agência Brasileira de Cooperação, do Ministério das Relações Exteriores.

11 TTO - Triple Trust Organization

12 OIT - Organização Internacional do trabalho.

${ }^{13}$ CEFE - Competência econômica por meio da formação do empresário.

${ }^{14}$ GTZ, agora GIZ - Deutsche Gesellschaft für Internationale Zusammenarbeit (Agência Alemã de Cooperação Internacional) é uma empresa privada internacional fundada em 1975 por Erhard Eppler, é especializada em projetos de cooperação e de desenvolvimento sustentável em escala mundial. Disponível em: https://pt.wikipedia.org/wiki/Deutsche_Gesellschaft_f\%C3\%BCr_Internationale_Zusammenarbeit 
conforme conceitos e ideias do autor Zabala (1998), principalmente relacionados aos conteúdos propostos para dinamizar a educação empreendedora. O termo "conteúdos" nesse trabalho refere-se às capacidades que se pretende desenvolver mediante os objetivos educacionais. Para evidenciar o caráter sistêmico dos conteúdos de aprendizagem foi utilizado o conceito "tipologias de conteúdos” do autor Coll (2009). Para Zabala (1998), o termo conteúdo quase sempre foi associado à apreensão de conceitos, mas esta ideia é uma visão restrita, visto que ela é apenas um dos objetivos educacionais. Para esse autor (1998, p. 24) “o aprendizado não deve se limitar as capacidades cognitivas porque os conteúdos de aprendizagem, amplamente entendidos, repercutem no desenvolvimento global do aluno".

Dessa forma, Coll (1996) apud Zabala (1998) destaca a importância dos conteúdos factuais, conceituais, procedimentais e atitudinais. Para Zabala (1998, p. 31) "essa classificação corresponde, respectivamente, às perguntas: O que se deve saber? O que se deve saber fazer? E como se deve ser?”. Seguem, no Quadro (1), os significados básicos das tipologias de conteúdos.

Quadro 1: Tipologias de conteúdos e significados.

\section{CONTEÚDOS}

Factuais

\section{SIGNIFICADOS}

Conhecimento de fatos, acontecimentos, situações, dados e fenômenos concretos e singulares.

Conceitos e princípios Os conceitos e princípios são termos abstratos. Os conceitos se referem a um conjunto de fatos, objetos ou símbolos que têm características comuns. Já, os princípios descrevem as mudanças provocadas nos fatos objetos ou situações, ou seja, descrevem as relações de causa e efeito ou de correlação entre estes fatores.

Procedimentais Um conteúdo procedimental é um conjunto de ações (regras, técnicas, métodos, destrezas ou habilidades, estratégias e procedimentos) ordenadas e dirigidas para a realização de um objetivo.

Atitudinais

Os conteúdos atitudinais compreendem as aprendizagens de valores, atitudes e normas.

Fonte: Adaptado de Zabala (1998).

Os objetivos para dinamizar a educação empreendedora nas escolas, as estratégias de ensino evidenciadas nessa pesquisa e os conteúdos conceituais e 
atitudinais foram extraídos dos recursos já mencionados. Já, a organização dos conteúdos procedimentais foi possível mediante a experiência de um dos autores com aplicações de jogos vivenciais. Para isso, foram identificados alguns conteúdos procedimentais, ou seja, determinadas tarefas - o que deve saber fazer - que o educando tem que realizar para aprofundamento dos conteúdos conceituais e atitudinais. Esses tipos de conteúdos são apresentados, juntamente com os objetivos e as estratégias de ensino, na seção resultados e discussão dessa pesquisa.

\section{Referencial teórico}

Lopes (2010, p. 17) diz que foi "a partir dos anos de 1970/1980 que a geração de novos postos de trabalho deveu-se mais à vitalidade das pequenas empresas, por isso a figura do empreendedor ocupou o centro dos debates". Diante disso, diversos países promovem, desde então, ações para garantir a competitividade por meio do empreendedorismo. Nesse ambiente, hoje há muitas iniciativas que impulsionam a educação empreendedora, que não são isoladas, ou seja, discutidas somente por uma classe de profissionais, mas sim debatidas por diferentes atores, até porque o desenvolvimento de pessoas impacta diretamente na prosperidade das nações. Delors (2012), por exemplo, nos trabalhos da comissão internacional para a educação no século XXI, ressaltou o autoemprego e o espirito empreendedor como diretrizes imprescindíveis ao desenvolvimento dos educandos.

Com o avanço desse tema houve mudanças significativas nas estruturas econômicas dos países, com destaques ao crescimento de pequenas empresas para impulsionar as economias. O Brasil, por exemplo, foi considerado, na atualidade, um dos países mais empreendedores do mundo, visto que sua taxa total de empreendedorismo (TTE) atingiu 34,5\%, o maior índice de todos os tempos, isso significa que cerca de 45 milhões de brasileiros, com idades entre 18 a 64 anos, têm negócios próprios (GEM, 2014).

Essa conjuntura, de certa forma, modifica as expectativas profissionais dos jovens, e hoje eles dividem opiniões quanto às opções de carreira, pois uns querem emprego e outros a criação de novos negócios. Por esse motivo, é necessário criar mecanismos educacionais que propiciem saberes para apoiar o desenvolvimento de jovens empreendedores por oportunidade em vez de empreendedores por necessidade, 
pois os primeiros são mais bem preparados para enfrentar os desafios. Para Dornelas (2008), o empreendedor por oportunidade é visionário e sabe aonde quer chegar, por isso cria uma empresa com planejamento prévio e visa à geração de lucros, emprego e riqueza. Já, o empreendedor por necessidade é aquele que se aventura na jornada empreendedora mais por falta de opção, por estar desempregado e não ter mais alternativa de trabalho.

Para evidenciar a educação empreendedora, Lavieri (2010) argumenta que, se a educação tem em sua essência o progresso social e o espirito empreendedor concentrase na inovação - conforme o conceito de empreendedor Schumpeteriano - as atitudes empreendedoras, portanto, são necessárias nos indivíduos para dinamizar o desenvolvimento dos países. Tanto Dornelas (2008) como Sarkar (2008) ressaltam a relação do empreendedor com inovação a partir do século XX considerando, para isso, as ideias do economista Joseph Schumpeter de 1949 que caracterizam o empreendedor como: aquele que destrói a ordem econômica existente pela introdução de novos produtos e serviços, pela criação de novas formas de organização ou pela exploração de novos recursos e materiais.

Diante dos estímulos à cultura empreendedora para assegurar os avanços econômicos e sociais, atualmente discutem-se temas sobre como devem ser conduzidas as práticas educativas para desenvolver competências necessárias à atuação eficaz do empreendedor diante dos desafios estabelecidos. Nesse cenário, há inúmeras iniciativas e práticas. Lopes (2010) comenta que um novo corpo de conhecimento acadêmico formou-se para respaldar a educação empreendedora a partir dos anos de 1980, por isso hoje já se tem muita experiência acumulada nacional e internacionalmente. Com relação à ideia de o empreendedorismo ser uma disciplina que pode ser aprendida, Lopes (2010), por exemplo, destaca os resultados do relatório da Conferência de Oslo da comissão Europeia de 2006. Nesse relatório constam dois estudos interessantes sobre resultados da educação empreendedora. No Green Paper on Entrepreneurship, de 2003, há evidências de que pessoas que tiveram a oportunidade de serem expostas ao empreendedorismo através da família, dos amigos ou educação mostravam-se mais inclinadas a considerar, com seriedade, a possibilidade de iniciar o próprio negócio. Já, o instituto de pesquisa do nordeste da Noruega mostrou em 2007, por meio de um estudo realizado junto às ações do programa de empresas “Junior Achievement - Young Enterprise", que a taxa de atividade empreendedora junto aos jovens participantes, de 
20 a 29 anos, foi de 15\%; maior do que a média da população geral europeia que é de $5 \%$ a $6 \%$.

Toda prática educativa orienta-se pelas finalidades educacionais, por isso é essencial definir o perfil desejado do educando, ou seja, delimitar as competências necessárias, as que darão a ele condições para realizar determinadas tarefas ou desafios.

\begin{abstract}
A prática educacional se orienta para alcançar determinados objetivos por meio de uma ação intencional e sistemática, portanto, os objetivos educacionais expressam os propósitos quanto ao desenvolvimento de qualidades humanas que os indivíduos precisam adquirir para se capacitarem, diante de um determinado contexto (LIBÂNEO, 2013, p. 132).
\end{abstract}

Quanto aos objetivos da educação empreendedora, Rabbior (1990) em

Guimarães (2002) apud Lopes (2010, p. 24) destaca:

$\checkmark$ Conscientizar a respeito do empreendedorismo e da carreira empreendedora, lançando semente para o futuro;

$\checkmark$ Influenciar/desenvolver atitudes, habilidades e comportamentos empreendedores;

$\checkmark$ Desenvolver qualidades pessoais relacionadas às competências necessárias para o mundo moderno como: criatividade, assumir riscos e responsabilidades;

$\checkmark$ Desenvolver conhecimentos, técnicas e habilidades focados no mundo dos negócios e necessários para a criação de uma empresa e, por último;

$\checkmark$ Auxiliar empreendedores e empresas, através de conhecimentos e ferramentas, para melhorar a competitividade.

Para Lopes (2010, p. 25) outra forma esclarecedora quanto aos objetivos da educação empreendedora, utilizada no projeto Entlearn - baseada em Hytti e O’Gorman (2004) se divide em quatro categorias:

$\checkmark$ Aprender sobre empreendedorismo;

$\checkmark$ Aprender a comportar-se de forma empreendedora (foco no indivíduo) e;

$\checkmark$ Aprender a tornar-se um empreendedor (Foco no negócio)

Lopes (2010) comenta que nos Estados Unidos adota-se o modelo de aprendizagem contínua por meio de estágios sucessivos com padrões nacionais de conteúdos. Nesse país, esse trabalho foi possível em função das participações do Centro de Recursos para Educação em Marketing e do Conselho Nacional Empreendedor (National Entrepreneur Advisory Council). Para essa autora, esses padrões, 
apresentados no Quadro (2), servem de base para desenvolver os currículos dos diversos níveis educacionais.

Quadro 2: Padrões americanos de conteúdos para educação empreendedora

\section{SEÇÕES}

\section{PADRÕES}

Processos empreendedores

Habilidades empreendedoras

Habilidades relativas à

prontidão para 0

empreendedorismo

Gestão financeira, Recursos humanos, Gestão da

Funções dos negócios
Traços comportamentais

Fundamentos de negócios, Habilidades interpessoais e de comunicação, Habilidades digitais, Economia

Administração financeira pessoal, Desenvolvimento

profissional.

Estratégia

Fonte: Adaptado de Lopes (2010).

Sarkar (2008, p. 61) diz que "apesar de os traços empreendedores serem mais prevalentes em alguns indivíduos do que em outros, o empreendedorismo pode ser promovido onde os traços empreendedores podem florescer”. Para este autor, uma pequena parcela da população nasce com capacidades inatas, características intrínsecas, mas outra parcela pode ser influenciada por fatores extrínsecos, principalmente pela educação e cultura.

Chiavenato (2012), partindo da verificação que um dos principais traços do comportamento empreendedor concentra-se na base motivacional para a realização, ou impulso para melhorar, reforça que as principais características que um empreendedor bem-sucedido possui, ou deve possuir, foram às identificadas por McClelland. McClelland (1987) propôs o riquíssimo estudo "Characteristics of Successful Entrepreneurs", apresentado em um simpósio sobre criatividade, inovação e empreendedorismo em Massachusetts. Para esse autor não havia, até então, nenhuma pesquisa com fortes evidências acerca da caracterização do empreendedor por meio de traços comportamentais. Por isso, envolveu-se em estudos, fundamentados por vários métodos estatísticos, por meio dos quais foi possível mapear bases motivacionais e traços comportamentais, essenciais ao sucesso empresarial. Para esse autor, os principais traços comportamentais, identificados em sua pesquisa, são: 
$\checkmark$ Iniciativa própria e busca intensa de oportunidades;

$\checkmark$ Perseverança, determinação e comprometimento;

$\checkmark$ Busca de qualidade e eficiência;

$\checkmark$ Coragem para assumir riscos, desde que sejam calculados;

$\checkmark$ Definição de metas e objetivos;

$\checkmark$ Busca de informações e de conhecimentos;

$\checkmark$ Planejamento e monitoramento sistemático, isto é, detalhamento de plano e controles;

$\checkmark$ Capacidade de persuasão e de estabelecer redes de contatos pessoais;

$\checkmark$ Independência, autonomia e autocontrole.

Diante do exposto observa-se que a educação empreendedora não se volta apenas ao ensino de conceitos, mas também contempla as habilidades comportamentais, ressaltando, assim, um caráter sistêmico no processo de formação do indivíduo. Se por um lado, diferentes habilidades devem compor a proposta desse tipo de ensino, por outro, Lavieri (2010, p.14) comenta que "raramente um currículo de educação empreendedora contempla o desenvolvimento de habilidades, o que indica a distância entre educadores e metodologias propostas”. Para Dolabela (1999) apud Lavieri (2010, p. 14) “o mais importante não é o conteúdo, mas sim o ensinar o empreendedor a aprender [...] o enfoque principal está no aprendizado através de processos de descoberta, sem respostas certas".

Para enriquecer esta visão, Lopes (2010, p. 29) diz que a educação empreendedora deve "enfatizar o uso intenso de metodologias de ensino que permitem o aprender fazendo, nas quais o indivíduo pensa de maneira diferente, buscando saídas e alternativas". Para isso, essa autora destaca as metodologias voltadas às aprendizagens baseadas em problemas e as que incentivam a cooperação, com ênfase em liderança, comunicação e trabalhos por meio de equipes.

Enfim, para impulsionar esses desafios são necessárias práticas educativas em diferentes estágios de formação da pessoa, principalmente junto às crianças e adolescentes, pois o ensino de competências duráveis, como de habilidades e atitudes, deve ser iniciado desde cedo. Além disso, uma proposta abrangente de conteúdos se faz necessária, pois conceitos, por si sós, não são capazes de resolver as necessidades das pessoas. Por último, mas não menos importante, deve-se educar para conhecimentos, habilidades, atitudes e bons valores, impreterivelmente com práticas vivenciais de ensino, as que colocam o aluno no centro da aprendizagem, mas não descuidam, jamais, dos aspectos teórico-científicos envolvidos. 


\section{Resultados e discussão}

Nessa seção, conforme métodos empregados, a proposta de práticas educativas acerca da educação empreendedora se materializa. Essa proposta não buscou esgotar todos os fatores envolvidos numa prática de ensino, adicionando, por exemplo, o dimensionamento de recursos utilizados, o papel do professor, ou ainda as estratégias avaliativas, mas sim, apresenta os objetivos, os tipos de conteúdos e algumas estratégias de ensino, essenciais para impulsionar o potencial do educando no ambiente empreendedor. Segue, no quadro (3), uma proposta parcial com objetivos e tipos de conteúdos, sem os procedimentais ainda, necessários ao planejamento didático das escolas com interesse nessa temática.

Nessa proposta foram considerados os seguintes direcionamentos: quanto aos objetivos, foram destacados os de Hytti; O'Gorman (2004) apud Lopes (2010), pois enfatizam o indivíduo e o negócio ao mesmo tempo, destacando, assim, tanto os aspectos comportamentais como os relacionados às funções dos negócios; Já, os conteúdos conceituais, sobre as funções dos negócios, foram extraídos do jogo vivencial Best Game. Esses conteúdos foram divididos em três grandes dimensões: o marketing do negócio, as operações da empresa e as finanças empresariais. Em cada dimensão há conteúdos conceituais específicos que, no conjunto, proporcionam ao educando uma visão abrangente sobre gestão de negócios; por último, os conteúdos atitudinais, relacionados aos traços do comportamento empreendedor, são os apresentados por McClelland (1987). No Best Game, por exemplo, que é um jogo empresarial vivencial, trabalha-se as condutas típicas do empreendedor que são, exatamente, os traços definidos por McClelland (1987).

Quadro 3: Objetivos e conteúdos para apoiar a educação empreendedora

\begin{tabular}{|c|c|c|}
\hline \multicolumn{3}{|c|}{ Objetivos e Tipologia de conteúdos } \\
\hline Objetivos & \multicolumn{2}{|c|}{$\begin{array}{l}\text { Aprender sobre empreendedorismo; aprender a comportar-se de forma } \\
\text { empreendedora (foco no indivíduo) e aprender a tornar-se um } \\
\text { empreendedor (Foco no negócio). }\end{array}$} \\
\hline $\begin{array}{l}\text { Conteúdos } \\
\text { Conceituais }\end{array}$ & Marketing & $\begin{array}{l}\text { Competitividade, tipos de estratégias empresariais, } \\
\text { mercado, segmentos de mercado, os quatro P's do } \\
\text { marketing: produto, preço, promoção e ponto de venda. } \\
\text { Estratégias de localização e equipe de vendas. }\end{array}$ \\
\hline Funções dos & Operações & 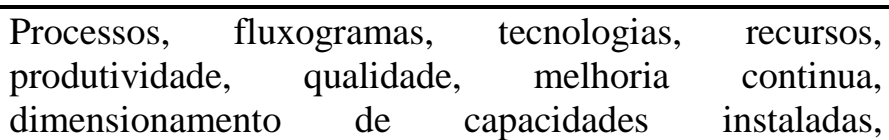 \\
\hline
\end{tabular}




\begin{tabular}{|c|c|c|}
\hline \multirow{2}{*}{ negócios } & & ociosidades. \\
\hline & Finanças & $\begin{array}{l}\text { Apuração de custos (variáveis e fixos); depreciação, } \\
\text { formação do preço de venda, ponto de equilíbrio } \\
\text { (operacional e financeiro) margem de contribuição, } \\
\text { capital de giro, controle de estoques, demonstração de } \\
\text { resultados econômicos, fluxo de caixa. }\end{array}$ \\
\hline $\begin{array}{c}\text { Conteúdos } \\
\text { Atitudinais } \\
\text { Habilidades } \\
\text { empreendedoras }\end{array}$ & $\begin{array}{c}\text { Condutas } \\
\text { típicas do } \\
\text { empreendedor }\end{array}$ & $\begin{array}{l}\text { Iniciativa e busca de oportunidades, persistência, } \\
\text { comprometimento, busca de qualidade e eficiência, } \\
\text { assumir riscos calculados, definição de metas e } \\
\text { objetivos, busca de informações, planejamento e } \\
\text { monitoramento sistemático, persuasão e redes de } \\
\text { contatos, independência e autoconfiança. }\end{array}$ \\
\hline $\begin{array}{c}\text { Conteúdos } \\
\text { Procedimentais }\end{array}$ & & Apresentados na sequência \\
\hline
\end{tabular}

Fonte: Adaptado de Hytti; O’Gorman (2004), Best Game (s/data) e McClelland (1987).

Até o momento, conforme Zabala (1998) foram destacados "o que se deve saber" e "o que se deve saber ser", relacionados, respectivamente, aos conteúdos conceituais e atitudinais. Daqui para frente, considerando as experiências de um dos autores desse artigo sobre aplicação de jogos vivenciais, são apresentados os conteúdos procedimentais, "o saber fazer", necessários ao fortalecimento da compreensão dos conteúdos conceituais e atitudinais. A divisão dos conteúdos procedimentais deu-se conforme as dimensões dos conteúdos conceituais propostos, ou seja, foram alocados no marketing do negócio, nas operações da empresa e nas finanças empresariais.

Segue a proposta com conteúdos procedimentais para a dimensão "marketing do negócio": descrever o perfil dos clientes: identificar quem são, onde estão e como falar com eles; pesquisar as necessidades dos clientes: saber o que eles querem - suas preferências, hábitos de consumo e de compra; desenvolver o projeto do produto: desenhar suas características - formato, tamanho, cor, modelo etc.; pesquisar os fornecedores: verificar as condições de ofertas de matérias-primas, materiais/insumos e mão de obra; analisar a concorrência: identificar quem são e conhecer seus diferenciais - preços, qualidade, inovação, prazo de entrega e outros; identificar as vantagens de localização da empresa: verificar critérios de localização tanto de empresas comerciais como industriais; escrever as políticas de preços e promoções: formatar uma proposta comercial, com base nas estratégias da empresa; desenhar uma proposta de treinamento: organizar informações necessárias para instruir os vendedores da empresa; estabelecer os indicadores de relacionamento com clientes: definir os tipos de desempenhos esperados nas relações da empresa com o mercado; 
pesquisar as variáveis externas da empresa: identificar as ameaças e as oportunidades considerando, para isso, a economia, a demografia, a cultura, a tecnologia, a política, a legislação e outros fatores.

Segue a proposta com conteúdos procedimentais para a dimensão "operações da empresa": treinar pessoas na fabricação dos produtos: passar instruções conforme características estabelecidas dos produtos, verificar o desempenho das pessoas e estabelecer os tempos padrões de fabricação; treinar pessoas na comercialização dos produtos; definir perfil do vendedor, instruir sobre produtos/serviços e formas de abordagens; definir os processos de produção: testar os processos e definir as etapas por meio das quais o produto pode ser fabricado, assegurando volume e qualidade; definir os processos de comercialização: prospecção de clientes, vendas e fechamento das negociações; pesquisar tecnologias: identificar novas tecnologias possíveis de serem empregadas no processo produtivo; mensurar a capacidade produtiva: estabelecer as metas de produção em função dos tempos padrões e das etapas de fabricação estabelecidas; definir o formato da matéria-prima: conhecer suas características e padrões de qualidade para não correr o risco de comprar fora das especificações técnicas; desenhar o fluxograma do processo: fazer uma representação gráfica do processo produtivo; estabelecer os indicadores de produtividade e qualidade: definir os tipos e desempenhos esperados no contexto das operações da empresa; desenhar o layout da empresa: fazer um esboço da sua estrutura física da empresa, envolvendo, prioritariamente, as áreas de produção e de comercialização; montar o organograma da empresa: representação gráfica dos níveis hierárquicos, dos departamentos (áreas funcionais) e das funções das pessoas; fazer o planejamento da produção ou comercialização: considerando, para isto, os estudos realizados sobre as capacidades produtivas/de comercialização da empresa.

Segue a proposta de conteúdos procedimentais para a dimensão "finanças empresariais": classificar os gastos fixos e variáveis da empresa: montar uma tabela com esses tipos de gastos; identificar as margens médias de contribuição dos produtos: os índices de contribuição para pagar os gastos fixos e gerar o lucro líquido; calcular o ponto de equilíbrio: um faturamento mínimo capaz de pagar somente os gastos totais da empresa; estabelecer as metas de produção/comercialização: considerando, para isto, o potencial de mercado, as capacidades produtivas ou de comercialização e o desejo de lucro líquido; fazer o orçamento empresarial: projetar as vendas, os gastos variáveis e fixos e o lucro líquido desejado. Isto se faz por meio do 
instrumento denominado de Demonstrativo de Resultado do Exercício (DRE); fazer o fluxo de caixa: em função das projeções de vendas e gastos, bem como dos prazos de recebimento das vendas e de pagamentos das contas, faz-se a projeção de caixa para identificar a necessidade de capital de giro; definir um modelo de controle dos estoques: como os estoques serão controlados, tanto físicos como monetariamente; identificar as necessidades de investimentos: em função das projeções realizadas estabelece-se a necessidade de capital para investimento, daí verifica-se se são necessários, ou não, os empréstimos bancários; fazer o balanço gerencial: desenhar a estrutura de ativos, passivos e patrimônio líquido; estabelecer indicadores econômicos e financeiros, necessários para mensurar os resultados finalísticos da empresa.

Sabe-se que não há melhores métodos de ensino para todas as ocasiões, mas sim aqueles que mais se adéquam às finalidades educacionais. M. Pereira (1992) apud Vieira; Vieira (2005) classifica as estratégias de ensino em dois grupos, uma centrada no professor, quando este está ativamente envolvido e outra no aluno, quando o professor tem um papel mais passivo comparativamente com o papel atribuído ao aluno. Sobre essa questão, não há sombra de dúvidas que as estratégias de ensino para apoiar a educação empreendedora se concentram mais em abordagens centradas no aluno, por meio das quais eles aprendem fazendo. Lopes (2010) reforçou isso quando disse que o aprender fazendo faz a pessoa pensar de maneira diferente, buscando saídas e alternativas.

Esse artigo não propõe um trabalho abrangente acerca das estratégias de ensino mais utilizadas no ambiente da educação empreendedora, mas percebe-se, em função de direcionamentos apresentados, que as metodologias ativas, como jogos vivenciais - por exemplo - são práticas que proporcionam resultados efetivos. Para Moran (2015), nas metodologias ativas o aprendizado se dá a partir de problemas e situações reais: os mesmos que os alunos vivenciarão depois na vida profissional, de forma antecipada durante o curso. Nesse ambiente, este autor evidencia os jogos na educação como uma das estratégias ativas de ensino. Para ele, os jogos e as aulas roteirizadas com linguagem de jogos estão cada vez mais presentes no cotidiano escolar, pois, para gerações acostumadas a jogar, a linguagem de desafios, as recompensas de competição e a cooperação são atraentes. 


\section{Considerações finais}

O que é que pode mudar nas escolas, caso o empreendedorismo seja, de fato, mais um tema transversal no currículo de ensino? Será que os professores estão preparados para tal realidade? Como as escolas trabalharão essa temática, com transversalidade ou ações no contraturno? Será que a escola suporta mais esse desafio? Para equilibrar essa carga, não seria interessante trabalhar os traços comportamentais desde cedo, mas deixar as funções de negócios para o ensino médio técnico? Esse artigo não buscou responder essas questões, mas sim destacou ingredientes-chave relacionados às práticas educativas para dinamizar a cultura empreendedora no ambiente escolar. Sabe-se que os jovens de hoje, diferentemente do passado, vão abrir mais negócios próprios como opção de carreira. Dessa forma, é preciso ampliar discussões sobre o papel da escola nesse contexto, uma vez que são elas as responsáveis por dinamizar saberes, sem os quais os educandos não se adaptam as necessidades sociais na atualidade. Enfim, a educação empreendedora propõe um olhar sistêmico à formação do educando, priorizando as competências duráveis, ou seja, as comportamentais, utilizadas em qualquer situação da vida, por isso não há duvidas sobre a importância desse tema nas escolas do Brasil.

\section{REFERÊNCIAS}

ASN. Empretec complete 20 anos no Brasil. Disponível em:

<http://www.df.agenciasebrae.com.br/sites/asn/uf/DF/empretec-completa-20-anos-deatuacao-no-brasil,80b53f316eb06410V gnVCM1000003b74010aRCRD>. Acesso em: 01 mar. 2017.

CAPE Centro. Best Game, manual do facilitador. Triple Trust Organisation, s/d. 94 p.

CAPE Centro. Repasse do Best Game, apostila s/d. 61 p.

CHIAVENATO, Idalberto. Empreendedorismo: dando asas ao espírito empreendedor. $4^{\mathrm{a}}$ ed. Barueri, SP: Manole, 2012.

COLL, César et al. O construtivismo na sala de aula. $6^{a}$ ed. São Paulo: Ática, 2009.

DELORS, Jacques. Educação: um tesouro a descobrir. $7^{a}$ ed. revisada. São Paulo:

Cortez; Brasília, DF: UNESCO 2012. 
DORNELAS, José Carlos Assis. Empreendedorismo: transformando ideias em negócios. $3^{\mathrm{a}}$ ed. Rio de Janeiro: Elsevier, 2008.

DORNELAS, José Carlos Assis. Empreendedorismo corporativo: conceitos e aplicações. Revista de Negócios, Blumenau, v. 9, n. 2, p. 81-90, abril/junho 2004. Disponível em: <file:///C:/Users/User/Downloads/Dornelas_2004_Empreendedorismocorporativo--_28067.pdf>. Acesso em: 04 mar. 2017.

EXAME. 71\% dos jovens querem empreender, diz pesquisa. Disponível em: $<$ http://exame.abril.com.br/pme/noticias/71-dos-jovens-gostariam-de-empreender-dizpesquisa>. Acesso em: 10 mar. 2017.

GEM -Global Entrepreneurship Monitor. Empreendedorismo no Brasil: relatório executivo (2014). Disponível em:

<http://www.sebrae.com.br/Sebrae/Portal\%20Sebrae/Estudos\%20e\%20Pesquisas/gem \%202014_relat\%C3\%B3rio\%20executivo.pdf>. Acesso em: 10 jan. 2017.

LAVIERI, Carlos. Educação empreendedora? In: LOPES, Rosemary A. (Coord.). Educação Empreendedora: Conceitos, modelos e práticas. Rio de Janeiro: Elsevier; São Paulo: SEBRAE, 2010.

LIBÂNEO, José Carlos. Didática. $2^{a}$ ed. São Paulo: Cortez, 2013.

LOPES, Rose Mary Almeida. Referenciais para educação empreendedora. In: LOPES, Rosemary A. (Coord.). Educação empreendedora: Conceitos, modelos e práticas. Rio de Janeiro: Elsevier; São Paulo: SEBRAE, 2010.

MCCLELLAND, David. Characteristics of successful entrepreneurs. Edited by Dr. George T. Solomon, U.S. Small Business Administration and Dr. Bruce G. Whiting, Kutztown University of Pennsylvania, v. 21, n. 3, Third Quarter. 1987.

MORAN, José. Mudando a educação com metodologias ativas. Coleção Mídias Contemporâneas. Convergências Midiáticas, Educação e Cidadania: aproximações jovens. Vol. II Carlos Alberto de Souza e Ofélia Elisa Torres Morales (orgs.). PG: Foca Foto-PROEX/UEPG, 2015.

ONUBR. Programa de educação empreendedora da ONU completa 20 anos no Brasil. Disponível em: <https://nacoesunidas.org/programa-de-educacaoempreendedora-da-onu-completa-20-anos-no-brasil/>. Acesso em 10 fev. 2017.

SARKAR, Soumodip. O empreendedor inovador: faça diferente e conquiste seu espaço no mercado. Rio de Janeiro: Elsevier, 2008.

VIEIRA, Rui Marques; VIEIRA, Celina. Estratégias de ensino/aprendizagem. Lisboa/Portugal: Instituto Piaget, 2005.

ZABALA, Antoni. A prática educativa: como ensinar. Porto Alegre: Artmed, 1998. 


\section{Como referenciar este artigo}

REINA, Fábio Tadeu.; AUGUSTO, SANTOS, Roberto Augusto dos. Educação Empreendedora: práticas educativas para dinamizar a ascensão pessoal e profissional dos alunos. Temas em Educ. e Saúde, Araraquara, v.13, n.1, p. 147-163, jan./jun. 2017. DOI <https://doi.org/10.26673/rtes.v13.n1.jan-jun2017.10.9592>. ISSN: 15177947.

Submetido em: 23/03/2017

Aprovado em: 20/07/2017 